\title{
Evaluation of IGRF 1980 Candidate Models
}

\author{
D. R. BARRAClOUGH
}

Geomagnetism Unit, Institute of Geological Sciences, Murchison House, West Mains Road, Edinburgh, U.K.

(Received March 3, 1982)

\begin{abstract}
The IGRF candidate models for the main field 1980 and the secular variation 1980-85 are compared with observations. The IGS and USGS secular variation models agree better with the global set of secular variation estimates than does the NASA model. The NASA and USGS models represent more closely than does the IGS model a spatially limited set of 1980 data.
\end{abstract}

\section{Introduction}

The latest revision of the International Geomagnetic Reference Field (IGRF) consists of four spherical harmonic models of the geomagnetic field at 1965, 1970, 1975, and 1980 and a model of the secular variation for the interval 1980 to 1985 . Three sets of models were submitted as candidates for the revised IGRF, one each from the Institute of Geological Sciences (IGS), NASA (Goddard Space Flight Center), and the U. S. Geological Survey (USGS). Evaluations of the three main-field models for 1980 and of the three secular variation models are described here.

\section{Secular Variation Models for $1980-85$}

The data used for this comparison were estimates of the secular variation at 1982.5 derived from a globally distributed set of observatory annual mean values. Differences between adjacent annual mean values were plotted and manual extrapolation was used to predict the secular variation at 1982.5. This gave a total of 166 values of $\dot{D}$ (the secular variation of declination) and 164 each of $\dot{H}$ (the secular variation of horizontal intensity) and of $Z$ (the secular variation of vertical intensity). In that these estimates were an important part of the data on which the IGS secular variation model was based (BARRACLOUGH et al., this issue), this comparison is biased slightly in favour of the IGS model.

The results of this comparison, shown in Table 1, indicate that there is little to choose between the three models in their representation of $\dot{D}$ but that the NASA model is not as good as the other two in describing the observatory estimates of $\dot{H}$ and $\dot{Z}$.

3. Main-Field Models for 1980

During 1979 and 1980 magnetic surveys of a large part of Saudi Arabia were performed. A total of 159 stations were occupied, at all of which declination $(D)$ was 
Table 1. Differences between observatory estimates of secular variation for 1982.5 and values computed from the three IGRF candidate models of secular variation 1980-85.

\begin{tabular}{|c|c|c|c|c|c|c|c|c|c|}
\hline & \multicolumn{3}{|c|}{$\begin{array}{c}\dot{D} \\
(\operatorname{arcmin} / \mathrm{yr})\end{array}$} & \multicolumn{3}{|c|}{$\begin{array}{c}\dot{H} \\
\text { (nT/yr) }\end{array}$} & \multicolumn{3}{|c|}{$\begin{array}{c}\dot{Z} \\
(\mathrm{nT} / \mathrm{yr})\end{array}$} \\
\hline & IGS & NASA & USGS & IGS & NASA & USGS & IGS & NASA & USGS \\
\hline Mean difference & 0.1 & 0.2 & 0.6 & 1 & -2 & -1 & 0 & -4 & -1 \\
\hline RMS difference & 3.3 & 3.9 & 3.7 & 11 & 16 & 11 & 13 & 22 & 16 \\
\hline Number of estimates & & 166 & & & 164 & & & 164 & \\
\hline
\end{tabular}

measured; horizontal intensity $(H)$ and total intensity $(F)$ were observed at 147 of the stations. For reasons of confidentiality, these data have not yet been used in any global models or charts. They thus form an independent data set, albeit of limited spatial extent, with which the candidate models can be compared.

The observations, corrected for instrumental effects by the three surveying companies concerned, were further corrected for diurnal variation and reduced to 1980.0 by the Geomagnetism Unit of IGS. These reduced values were compared with values of $D, H$, and $F$ computed from the IGS, NASA, and USGS models of the main field for 1980 . The mean and root mean square (RMS) differences are shown in Table 2, which indicates that all three models are comparable in their agreement with the declination data, whereas the IGS model is poorer than the other two as a representation of $H$ and $F$ in Saudi Arabia. This is not entirely unexpected as the IGS model is closely similar to the model of BARKER et al. (1981) whose primary purpose was to represent $D$ as well as possible for world charting.

\section{Conclusions}

On the basis of the comparisons described here, the IGS and USGS secular variation models represent the secular variation in all three elements equally well. The NASA model has larger residuals from the observatory estimates of $\dot{H}$ and $\dot{Z}$ and is slightly poorer at representing $\dot{D}$. As far as the main-field models for 1980 are concerned, all three candidates represent the declination observations in Saudi Arabia equally well. Over this restricted region, the IGS model does not fit the observed $H$ and $F$ values as well as the NASA and USGS models. The latter two models are comparable in their ability to fit the observations of all three elements.

Table 2. Differences between recent observations in Saudi Arabia and values computed from the three IGRF candidate models for 1980 .

\begin{tabular}{|c|c|c|c|c|c|c|c|c|c|}
\hline & \multicolumn{3}{|c|}{$\begin{array}{c}D \\
(\operatorname{arcmin})\end{array}$} & \multicolumn{3}{|c|}{$\begin{array}{c}H \\
(\mathrm{nT})\end{array}$} & \multicolumn{3}{|c|}{$\begin{array}{c}F \\
(\mathrm{nT})\end{array}$} \\
\hline & IGS & NASA & USGS & IGS & NASA & USGS & IGS & NASA & USGS \\
\hline Mean difference & 0.8 & 3.1 & 1.7 & -192 & -36 & -44 & -70 & 15 & -2 \\
\hline RMS difference & 9.7 & 10.0 & 9.6 & 202 & 73 & 76 & 99 & 71 & 69 \\
\hline $\begin{array}{l}\text { Number of } \\
\text { observations }\end{array}$ & & 159 & & & 147 & & & 147 & \\
\hline
\end{tabular}


This paper is published with the permission of the Director of the Institute of Geological Sciences.

\section{REFERENCES}

BARKER, F. S., D. R. Barraclough, and S. R. C. Malin, World magnetic charts for $1980-$ spherical harmonic models of the geomagnetic field and its secular variation, Geophys. J. R. Astr. Soc., 65, 525-533, 1981.

Barraclough, D. R., B. M. Hodder, and S. R. C. Malin, The IGS proposal for the new International Geomagnetic Reference Field, J. Geomag. Geoelectr., this issue, 351-356, 1982. 